\title{
The Need to Train Librarians in Data Related Issues
}

\author{
by Julia Dawn Paris \\ University of the Western Cape
}

\section{Introduction}

The training of librarians in data related issues has become an educational imperative emanating from the technological advances experienced globally. The dramatic strides in technological developments are causing major expansion in the way that end-users access information. This sudden explosion of information has caused a shift from the print to the electronic mode, which in turn has led to a shift from ownership to access. Academic librarians make information accessible for research in academic libraries by placing at the individual's disposal vast resources of information to satisfy information needs. Academic librarians are thus challenged to redefine their service philosophy. A reconsideration of roles and mindsets are the profound changes that will have to be effected.

Parallel to the developments in technology, the political changes and the unfolding transformation process in South Africa necessitates academic librarians to reconsider their information provision strategies to redress imbalances.

\section{Statements of Objectives}

In this paper I will focus on the following:

(i) the impact of technology on academic libraries;

(ii) the impact of technology on the client of the academic library, with special reference to the University of the Western Cape; and

(iii) the changing roles that academic librarians are required to play.

The abovementioned issues will be contextualized within the framework of the political changes occurring in South Africa.

\section{Clerification of Concepts}

For the purpose of this paper, data is defined as facts, statistics or information that can be analysed. Knowledge is defined as familiarity gained by experience. It is also viewed to be a person's range of information or theoretical or practical understanding. Information is viewed as desired items of knowledge. One notes a diversity in the definition of information. This is in view of the fact that it is deemed to be intangible and only encountered operationally by its effects. It is suggested to be derived from data, and can be accessed through print and computerized machinery for utilization (Zorckoczy, 1988: 11).

Training as used in this paper refers to the concern with making the best use of the Human Resources in an organization by providing them with the appropriate instruction to acquire the necessary skills for their jobs (Statt, 1991: 154).

\section{Impact of Technology on Academic Librarries}

Internationally, the age of computers have certainly impacted on the traditional manner of doing things in a library. The dynamic nature of information generation, management and use, as well as the proliferation of publications, force the library environment to either adapt or die. Microcomputers have streamlined the operational workflow of routine functions as well as enhance the online search process. Cataloguing and circulation automation are providing more effective service and better control over collections. Computer technology effected various ways of accessing information more speedier through networked electronic mail facilities. It now allows librarians to automatically logon to local and remote systems and download search results for later printing. This is causing a major shift from libraries' provision of information from own collections to that of access to remote regional, national and international collections, databases and networks. Advanced technology also gave rise to the virtual library - a concept used to denote remote access to the contents and services of libraries and other information resources, combining an on-site collection of current and heavily used material in both print and electronic form with an electronic network which provides access to, and delivery from, external worldwide library and commercial information resources. This is a transformation with dramatic results for research which cannot be ignored. Computer technology has indeed made it possible for libraries to establish networks, based on co-operation and resource sharing, with each other and with other information centres. The concept of networking, understood to be the building of contacts among professionals, has been given new meaning by the academic library's utilisation of technology. Here one thinks especially of the INTERNET, which is seen as the network of networks. It brings together people, databases, and networks. Through technology eager use is also made of periodical indexes and reference works on CD-ROMs (Compact disc read-only-memory). It is interesting to note that this transformation, brought about by technology, does merit a lot of adjustment. This is demonstrated in library school curricula which, today, include a module on Information Technology or a complete course on computer science. It is true to say that the increasing complexity and sophistication of information technology requires a high degree of specialized technical 
knowledge. This requirement has far reaching implications for the future training of academic librarians. Academic librarians should learn how to exploit new technology to the benefit of their user's information needs. They have a responsibility to require the knowledge and skills necessary to use and teach the most efficient information techniques the current technology makes possible. A proactive and flexible manner is also required if academic librarians want to take up the challenge of technology, to interact and communicate effectively with clients who may not only be unfamiliar, but also uncomfortable with information technology. Therefore, training and retraining should be high on the strategic priority list of academic libraries.

In South Africa, academic librarians and end-users experience the convenience of information made easier and speedier by sophisticated machinery. On the other hand, they experience difficulty in the accessing of the information and information overload. Information overload occurs when locating too much information on the given topic. This dilemma creates a feeling of being overwhelmed and overloaded and this could result in a situation of frustration and anxiety. If a user is not able to understand the automated system used for an online catalogue at any academic library, or the systems potential to give information, or know how to sift and sort through the plethora of online information, it immediately results in information poverty by creating a barrier between the user and the information needed. Hence, information technology becomes a problem when it deprives users of information, especially if the information is to satisfy basic needs as experienced by the majority of people in South Africa.

South Africa is a 'new kid on the block' in the development of technology and the application thereof. Estimations claim that information technology is developing at an annual rate of $35 \%$ in South Africa. This is viewed to be very slow in comparison with developed countries where information technology is doubling, if not tripling, at that rate every four years. My major concern is with the extent of the impact of this development of technology, however slow, on the information impoverished people of South Africa. The South African academic libraries, and in particular the University of the Western Cape (UWC) have been influenced by the global information explosion. The access of our users to local, national, international databases and networks, has made it necessary for the librarians to take an objective look to what is happening. I agree with Makhubela (1995: 15) who states that "though this situation is not necessarily unique to UWC, it becomes especially critical, given that many students at UWC come from economically deprived and disadvantaged communities". The realization then, that technology is affecting the way that librarians provide access to information should become a catalyst for change. However, outdated mindsets and curricula make it downright impossible to take up the challenges posed by the shift and increased user expectations.
Challenges facing librarians in South Africa are not only caused by the technological developments, but also by the major political change from an oligarchic, Apartheid society to that of a democratic one. Great educational inequalities, major illiteracy problems, lack of a reading culture, lack of school libraries are some of the stark realities academic librarians are faced with. The Nationalist Apartheid government fostered a library and information service characterized by a traditional approach as was followed by many of the developed countries. It was focussed to benefit the educated user community, was literacy based, with collections comprising of predominantly books, and an emphasis on facilities and collections instead of the needs of users. In a nutshell it served the needs of the dominant white culture and class (Nepi, 1992: 54). The transformation process now underway calls for the library and information service to also undergo transformation and address the social responsibility of libraries. It calls for a shift in emphasis from collections to needs of users. It also challenges librarians to use information as a source of development and empowerment in the education of all those served. In the academic environment librarians need to learn to facilitate the learning environment of disadvantaged students even if it means teaching them step-by-step how to use the technology in its basic forms e.g. OPACS, and later teach them how to access CD-ROM databases and other remote online networks through Information Literacy Programmes.

\section{The Impact of Technology on Clients}

Industrial progress requires a versatile and skilled labour force. This could be effected by well planned education and training strategies. Information needs vary according to levels of education and socio-economic status. It is important to assess what it is that information end-users need and want. To end-users accessibility of information is one of the primary issues of concern in satisfying information needs. No matter how organized the information, it will not realize its value until it is made known and put to effective use.

A generalization reflected in international literature is the idea that undergraduates usually labour under time constraints. Also, that their information needs are most often met by the collections of their own institution. Further, that depth of reference queries are not so complex and that less reference assistance is required. This argument definitely assume a situation where undergraduates have been exposed to adequate education, school libraries, and have a sound economic background.

At an institution such as UWC, a lack of factors noted above, combined with problems of language, render undergraduates incapable of having a basic understanding of their research topic under investigation. Minimum or no knowledge of basic reference sources, inability to verbalise information needs are other shortcomings encountered by academic librarians. 
Post-graduate and faculty needs are viewed as extending beyond the resources of their own institution. The research of these clients represent unique contributions to the knowledge base of disciplines. Therefore, their demands on reference services are more specific and exhaustive. For them the academic library extends into the resources of other information centres through inter-library lending services. With the advent of online searching on remote databases and networks ' the world become their campus'. The appearance of computer accessible information databases have changed the way researchers search for information. Some scholars rely almost entirely on computerized sources for current citations to published research in progress. This is creating great expectations toward academic libraries to provide the necessary mechanisms to access these sources.

At UWC our post-graduate and faculty needs do not differ as widely as that experienced internationally. However, with post-graduate students the librarians still have the responsibility to teach the most efficient information techniques the current technology in the library makes possible. I wish to reinforce Benson's (1995: 57-69) utterance when he said that "our enthusiasm about the new technologies should not outstrip our ability to provide adequate service to those for whom we acquire the services and may cause us to overlook real needs". I firmly believe that we have a responsibility to be sensitive to research needs of the entire academic community we serve. To reflect this sensitivity, we need to conduct use and needs studies to ensure acquisition of the databases and networks.

\section{Changing Roles of Academic Librarians \\ Traditional role of librarians}

Previously, librarians emphasised preservation of books, making them accessible through cataloguing and classification, and offering a client advice and guidance service. Librarians were only required to know where information could be found rapidly to answer the client's need or questions. Librarians were viewed as custodians of collections of library material instead of proactive individuals. This situation is still prevalent in many academic libraries in developing countries.

\section{New roles of librarians}

In the developed countries, the paradigm shift from traditional to electronic libraries have changed the way librarians execute their duties today. The expectations created by this paradigm shift resulted in the need for librarians to adopt a new vision and a new mission to meet users information needs. They are faced with new issues, and new challenges brought about by the increasing use of information technology in the library environment and the rapid changes occurring in this area, understanding of what librarians duties are and the new attitudes that should result from this change in mindset.

There is also the added challenge of helping clients to manage the information overload that came about as a direct result of this new era. Clients must be assisted to sort through the wealth of information and make wise decisions about what they need. There is a challenge posed at academic libraries to shift the emphasis from physical documents to individuals with needs; from document delivery to information management and transfer; and from question-answering to problem-solving. Librarians are challenged to move beyond quantity to quality. A general view seems to be that although this shift has occurred, librarians continue to be more concerned with delivery of documents and have not started to focus on the delivery of contents or the data and information contained in the documents. My contention is that this is due to the failure to grasp that there is a need for this new vision. There should be a move towards acceptance of the facts that major paradigm shifts are creating new definitions of what librarians roles are to be in the technological library environment. We face expanded demands on our time and skills and are afforded a tremendous opportunity to assist students and faculty to solve their research problems. Requisite skills that need to be acquired include: competencies ranging from communication skills to knowledge of database searching techniques; sifting and analysis of information; and the reduction of the amount of information provided to the user. Larry Benson (1995: 58) postulates that "as attitudes toward the use of automated systems change, so must the roles of academic librarians. They face expanded demand on their time and skills and have a tremendous opportunity to assist students and faculty to solve their research problems".

The academic librarian is called upon to serve in overlapping roles namely as information specialist; teacher/trainer; and as consultant. Depending on the library's priorities, elements of all three roles will enter into the professional librarian's position. As information specialist, the librarian will be called upon to provide adequate access through adequate resources for optimum usage. As teacher, the librarian will have to teach library, information, and technology literacy skills. This includes the teaching of critical thinking skills to assist clients to become active, independent and confident users of information technology. As consultant the librarian is called upon to participate in academic curriculum design and assessment projects and to provide expertise in the selection, evaluation and use of materials and emerging technologies for the delivery of information and instruction, as well as translating curriculum needs into academic library program goals and objectives. A reluctance to assume this role would deny the faculty and administration the benefit of the valuable insights academic librarians have in these areas. It would also minimalize the importance of the academic library to academic outcomes. This expanded role of the academic librarian, brought about by information technology has great potential for improved educational outcomes.

At UWC, the role played by academic librarians has not 
changed very much. The new issues and challenges of technology have not resulted in a radical change of roles yet. In fact, the technology applied in information provision and access have not been exploited to its fullest potential. Lack of resources have made it impossible to initiate a process of exposing end-users to networks like the Internet. Language problems and other cultural barriers add to the existing complexities of users social backgrounds. The predominant roles thus played are primarily those of instructor in library skills, information provider, faculty liaison and collection developer. Lack of adequate staffing and specialized skills contribute to a work overload which are some of the factors slowing down the move toward the real role of facilitation and empowerment.

\section{Recommendations for Training Strategies:}

The training of librarians should be understood within the broad framework of Human Resource Development and Capacity Building within the transformation paradigm of South Africa. In order to play a proactive role in facilitating information acces and its proper use, it is imperative to look at the role librarians can and should play. The suggestions posed in this section are not proposed as solutions, but should serve as useful information that could assist in appropriate applications of training strategies.

Any training or retraining embarked upon by librarians in South Africa, should be done in line with the needs of those wanting and needing the services. The bottom line for training should always be improvement and efficiency of services to clients. This is especially seen against the background of cultural diversity within the population as well as their previous exposure or non-exposure to information. Reference librarians need to be equipped to become more sensitive to cultural diversity and in this new technological environment develop more effective communication skills to understand the multi-cultural aspects of information seeking behaviour. In order to make a difference, these aspects should be inculcated through the curriculum design at Library school entrance level. Continuous education efforts to ensure lifelong learning in multi-cultural information provision and the evalution of performance should also become a priority.

The majority of users of the historically marginalised institutions come from a background of poverty, illiterate parents, overcrowded homes, lack of proper housing, lack of reading facilities, oral tradition and lack of proper schooling, to mention only a few. For these users information is geared towards coping to survive. Librarians need to be equipped to understand this dilemma experienced by the majority of users and to devise strategies to effectively address it so that they become instrumental in helping users.

Information technology and other mechanisms should be applied to enhance the development process of information seekers in South Africa, not impede it. Librarians must be equipped to break down the barriers which hinder information access. The unfolding transformation process brought about a new dimension of complexity in the form of all the challenges facing academic librarians. Librarians should provide an unthreatening atmosphere in which users could access the necessary information. Librarians should also become instrumental in computer aided instruction programme development.

Training must include elements of basic data analysis, networks, and network search commands, the nature of interfaces, search software of specific social science and other databases. General training in the nature of all databases and networks is imperative. Training in end-user instruction, to ensure optimum utilization of these costly resources, is necessary. In order to instruct end-users, librarians themselves need to be trained in how to access, search and interpret different databases.

The intention with strategies mentioned should be to use existing resources. The challenge is placed before tertiary institutions and other academic alliances to respond to the training and continuing education needs of the academic librarians by transforming themselves in the way they operate. This statement is made in view of the fact that there is considerable competence and skills existing within the various alliances of the Library and Information Service, but outdated principles regard users as passive consumers of information instead of an active participant in the information process. Within the South African situation, there are no simplistic answers. Here academic librarians face formidable challenges, but also lots of opportunities to make a difference.

Training should also address all levels and needs in terms of how to supplement current awareness of Information technology, how to do retrospective searches and how to use technology in the social science and other related fields.

Basic training is required to increase the awareness of people about the possibilities offered by the new technology and teaching them effective ways to make use of the equipment. This is the equivalent of teaching people how to use the computerized catalogues. A second kind would be training needed to become fully familiar with a complex word processing or database software package. If the training is neglected, the full benefits of the facilities will not be realized and the drawbacks will be magnified (Boston,G,1994:331-337).

The introduction of new electronic services has implications for virtually all library staff. Inevitably, as electronic information systems expand, workloads will change and resources, both human and financial, will need to be redirected. Successful implementation and user satisfaction in the electronic environment, will only be achieved by a highly trained and skilled library workforce. These will 
include increased knowledge of automated systems and electronic communications, as well as the hardware such as workstation networks.

Furthermore, it is important that information workers continue to be active in influencing the newly emerging national and international standards for electronic information, e.g., standards for bibliographic control and for citing articles. "Some electronic network travellers will fearlessly set off on their own. Others will still rely on librarians to drive the tour bus" (Woodward, 1994: 44). In the UK, the Library Association is encouraging librarians and information workers to analyze the contents of online information systems, databases and CD-ROMs in the same way that librarians have critically analyzed the contents of reference books for accuracy and up-to-dateness.

The information era, as previously noted, puts before us more information than can be consumed and used. The sifting and analysis of information, and the reduction of the amount provided to the user, is an equally important responsibility that is based upon the traditional skills of information workers. The quality and standards of service provision has become an important factor too. Agreed and published standards or guidelines are mechanisms to be used, because they are important factors toward improvement in the provision of services. The professional librarian also has the responsibility to maintain his/her level of knowledge, skills and expertise given the speed of change enhanced by the information technology and telecommunications developments. It is our responsiblity as well as those of employers to ensure that the knowledge base and expertise of information workers is kept up-to-date. It should be made mandatory by Library Associations.

Literature suggest a code of ethics or conduct as the machinery to exert pressure, should information workers fail to meet the responsibilities as set out above. In training, librarians should be charged with learning the structure of online libraries, the mechanics of searching, and the relationship between database content and user questions. Librarians should be trained not only to focus on specific databases within their areas of specialization, but also to look at general news databases which transcend subject discipline. To understand this magnitude of online library collections, a major conceptual shift in thinking must occur. The ability to search full-text articles makes the service unique, and poses special challenges. The importance of constructing precise search statements, critically selecting words and utilizing appropriate commands to narrow the retrieval are some of the special instructional challenges for reference librarians (Adalian \& Rockman, 1995: 99-113).

Identifying, locating and using networked information can only be accurate with the help of an intermediary specialized information workers who are the links between the information seekers and the information in the databases.
In the networked environment it is easy to become suddenly overwhelmed with a large volume of information. In the absence of user driven filtering of information librarians are called upon to play the role of filtering and interpreting the information for those who choose to use libraries.

\section{Stakeholders to Assist in Training}

The many challenges posed to academic librarians cannot be carried by them alone. What will be required, are the effective partnerships of all major stakeholders within the field of Library and Information Services. Training structures for librarians already exist, but should be effectively harnessed for continuing lifelong education. Stakeholders who should play a vital role in the education and re-education of academic librarians in South Africa are the African Library Organization (ALASA), the Inter Resource Forums, The Library and Information Workers' Organization (LIWO) and the South African Institute of Librarianship. These organisations should pool their resources and professional skills to provide a vehicle for Information Workers throughout South Africa to benefit from a broad range of professional expertise.

Other stakeholders identified are: the vendors of technological and commercial products - by giving basic training in their software; library schools - by updating and redesigning curricula as the changes in the information provision environment occur; University and Academic Library Administrators - through strategic planning of inservice training programmes in word processing, database-, online network searching and information management skills; and finally Government Departments who should make the necessary funds available to acquire the technology and training facilities needed to empower and build the capacity of academic librarians.

\section{Conclusion}

The training of academic librarians in data related issues is crucial if they want to play the new role of facilitator in the technological environment of the academe. To be able to do so academic librarians have to leave their comfort zones as custodians and become proactive role players in the information provision for development and progress. It is my belief that South Africa can learn valuable lessons from the international experience. However, priorities for training need to be constructed in accordance with the prevailing needs and conditions in South Africa, and not simply in relation to abstract theories or first world research findings.

\section{References}

Adalian, Paul T \& Rockman, Ilene F. (1995) Issues in implementing and teaching the Lexis/Nexus services in an undergraduate library. The Reference Librarian, 48: 99-113.

Benson, Larry D. (1995) Scholarly research and reference service in the automated environment. The Reference 
Librarian, 48: 57-69.

Boon, J.A. (1992) Information and development towards an understanding of the relationship. South African Journal of Library and Information Science, 60 (2): 63-74.

Boston, George (1994) New Technology - Friend or Foe. IFLA Journal, 20 (3): 331-337.

Bowden, Russel (1994) Professional Responsibilities of Librarians and information Workers. IFLA Journal, 20 (2): 120-129.

Chatman, Elfreda A. \& Pendleton, Victoria (1995)

Knowledge gap, information - seeking and the poor. The Reference Librarian, 49/50: 135-145.

Diaz, Karen R. (1994) Getting started on the Net. The Reference Librarian, 41/42: 3-24.

Faries, Cindy (1994) Reference librarians in the Information Age: Learning from the past to control the future. The Reference Librarian, 43: 19-28.

Figueiredo, Nice (1992) Information as a tool for development. The International Information and Library Review, 24 (3) Sept.: 189-201.

Gerber, P.D; Nel, P.S. \& Van Dyk, P.S. (1994) Human Resource Management. Halfway House: Southern Books Publishers.

Hopkins, Richard L.(1995) Countering information overload: the role of thelibrarian. The Reference Librarian, 49/50: 305333.

In Focus (1995) Human Science Research Council Bulletin, Feb/March: 37-43.

Library and Information Services. (1992) Report of the NEPI Library and Information Services Research Group: a project of the National Education Co-oordinating Committee Cape Town: Oxford University Press.

Liu, Mengxiong. (1995) Ethnicity and information seeking. The Reference Librarian, 49/50: 123-133.

Makhubela, L \& Koen Z. (1995) Another angle on access: information literacy and student Learning. Academic Development, 1 (1): 13-19.

McCallum, Sally H. (1994) Connectivity for Libraries and Information Services - Introduction. IFLA Journal, 20 (2): 145-146.

Mchombu, Kingo. (1991) Which Way African Librarianship. International Library Review, 23: 183-200.
Pask, Judith M \& Snow, Carl E. (1995) Undergraduate Instruction and the Internet. Library Trends, 44 (2) Fall: 306317.

Sisson, Loren \& Pontau, Donna (1995) The changing instructional paradigm and emerging technologies: New opportunities for reference librarians and educators.

The Reference Librarian, 49/50: 205-215.

Statt, David (1991) The Concise Dictionary of Management. London: Routledge.

Summerhill, Craig A. (1994) Connectivity and Navigation: An overview of the Global Inter-Networked Information Infrastructure. IFLA Journal, 20 (2): 147-157.

Sykes, J.B. (Ed.) (1982) Concise Oxford Dictionary. Oxford: Clarendon Press.

Weibel, Stuart R. (1995) The World Wide Web and emerging Internet Resource discovery Standards for scholarly literature. Library Trends, 43 (4) Spring: 627-644.

Westerman, Mary. (1989) Computers in Academic Libraries. Health Science Libraries - micros and medicines. Catholic Library World, 60 (4) Jan/Feb: 150.

Woodward, Hazel. (1994) The impact of Electronic Information on Serials Collection Management. IFLA Journal, 20 (1): 35-45.

Zorckoczy, P. (1988) Information technology. Oxford: Clarendon Press.

1. This paper has been presented at the CSS96/IASSIST conference at Minneapolis, University of Minnesota, May 12 - 19, 1996.

Julian Dawn Paris, Subject Librarian - Economic and Management Science, University of the Western Cape, Private Bag X 17, Bellville, South Africa. 